\title{
Geomagnetic Basement Relief of the Northern Taiwan Area
}

\author{
Kuang-Jung Chen ${ }^{1, *}$, Chao-Ming Wang ${ }^{1,2}$, Shu-Kun Hsu ${ }^{3}$, and Wen-Tzong Liang ${ }^{4}$
}

(Manuscript received 13 October 2000, in final form 1 May 2001)

\begin{abstract}
A detailed magnetic survey has been carried out in the northern Taiwan area in order to determine the topographic surface of the magnetic basement. This survey covers an area of about $900 \mathrm{~km}^{2}$, and totally the observation point is 269. After geomagnetic corrections of the observed data, the magnetic anomaly map was obtained. For the purpose of resolving the deeper (relative to the shallow effects) magnetic basement, a low-pass filter was applied to the magnetic anomaly to obtain a smoothed magnetic anomaly. Thirteen profiles were designed to cross and cover evenly the smoothed geomagnetic anomaly in the study area. These geomagnetic anomaly profiles were inverted to obtain the magnetic basement profiles by trial and error method. Compiling these 1-D magnetic basement profiles, we outlined the 2-D magnetic basement relief. The pattern of the relief of the geomagnetic basement shows that the depth is ranged from 2.6 to $6 \mathrm{~km}$. There exists a basement high under the Tatun volcano area. Compiling with the topographic relief, we can find that they correlate to each other well, except for a contravention in the mountainous area surrounding the Taipei basin. This converse can be explained by supposing that tectonic forces lifted the mountainous area after the basement was formed.

In order to verify the "truth" of the solution, we calculated the theoretical geomagnetic anomaly using the model we have inverted. Comparing the result with the observed geomagnetic anomaly map, we can find that they are quite similar to each other, with only a small variance.
\end{abstract}

(Key words: Magnetic survey, Magnetic anomaly, Magnetic basement)

\section{INTRODUCTION}

A regional magnetic survey covering an area of about $900 \mathrm{~km}^{2}$ has been conducted in the

\footnotetext{
${ }^{1}$ Department of Earth Sciences, National Taiwan Normal University, Taipei, Taiwan, ROC

${ }^{2}$ Industrial Development Bureau, Ministry of Economic Affairs, Taipei, Taiwan, ROC

${ }^{3}$ Institute of Geophysics, National Central University, Chungli, Taiwan, ROC

${ }^{4}$ Institute of Earth Sciences, Academia Sinica, Taipei, Taiwan, ROC

${ }^{*}$ Corresponding author address: Prof. Kuang-Jung Chen, Dep. of Earth Sciences, National Taiwan Normal University, 88 sec 4 Ting Chow Rd., Taipei, Taiwan, ROC; E-mail: kjchen @cc.ntnu.edu.tw
} 
northerm Taiwan area. Major geologic features in the surveyed area are the Linkou Terrace in the southwest, the Tatun volcanic groups within the middle, and the Taipei basin in the midst. Because of interest in the seismicity, volcano activity, petroleum exploration, and geothermal resources, some studies, including gravity (Tzou and Yu 1987; Chen and Yeh 1991; Yang et al. 1994), seismology (Chen and Yeh 1991; Chen et al. 1995; Chen 1998), seismi c (Wang et al. 1994), magnetic (Yang et al. 1994), electromagnetic (Chen and Hsieh 1994), geology (Chen and Wu 1971; Lee et al. 1999; Yen et al. 1984) and well logging (Hsieh et al. 1994) have been done in this area. In this study, a detailed magnetic survey is conducted in order to infer the relief of the magnetic basement.

A magnetic anomaly map generally provides fundamental reconnaissance of a geological province. These maps yield basic information reflecting the physical properties of the underlying rocks or sediments. A magnetic anomaly map is certainly important to investigations of regional tectonics by providing information in geological boundaries and the volcanic nature of underlying sources.

In many magnetic surveys, the objective is to describe the boundary between sedi mentary basins and surrounding areas where the basement is shallow. Such information can often be obtained by visual inspection of a magnetic map. A basin can be characterized by smooth contours and low magnetic relief, while the surrounding platform area shows steep gradients and high relief in the magnetic contours. Magnetic contours can look so deceptively similar to contours of subsurface structure that it is easy for those not familiar with magnetic maps to interpret the magnetic features indicated by the contours as if they were structural.

Magnetic effects at the earth's surface from buried bodies of a given shape and magnetization can be calculated from potential theory by methods similar to those used for determining the gravitational effects of density contrasts associated with the same bodies. Forward modeling is a basic approach to the interpretation of the underlying magnetic bodies. This kind of modeling is an "art" of estimating the geometry of the source or the distributors of magnetization within the source by trial-and-error modeling. There are many different forward modeling algorithms available for calculating the precise field of hypothetic source. The result is compared with the observed data, and the model is adjusted in order to improve the fit for a subsequent comparison. In this study, algorithms using the generalized analytic signal to determine the depth to magnetic source developed by Hsu et al. (1996) were applied to do the profile and surface modeling.

\section{GEOLOGIC SETTING}

Taiwan is located at the convergent boundary between the Eurasian plate and the Philippine Sea plate. Plate interaction is marked primarily by the collision of Luzon volcanic arc with the Asiatic continental margin. The orogen located in northeastern Taiwan is presently involved in the subduction tectonism associated with the Ryukyu arc (Lee and Wang 1987; Suppe 1981, 1984; Tsai et al. 1977, 1981; Wu 1978). The subduction of the Philipp ine Sea plate beneath the Ryukyu arc is marked by an east-west planar seismic zone approximately 50 kilometers thick located near Hualien at $24^{\circ} \mathrm{N}$ (Tsai 1978). The seismic zone dips north ward to a depth of around $150 \mathrm{~km}$. The position of this depth is right underneath the Tatun and Keelung 
volcano groups in northern Taiwan and the northeastern offshore volcanic islets. The tectonic framework may therefore be dominated by the distribution of Quaternary volcanics of the northem Taiwan area (Tsai et al. 1977).

In northeastern Taiwan, the subduction of the Philippine Sea plate beneath the Ryukyu arc dips around 45 degrees northward. The volcano groups in northern Taiwan and volcanic islets offshore northern Taiwan is considered to be the western extension of the Ryukyu volcanic arc. The volcanic events of northern Taiwan are indicated by K-Ar age data to have occurred from Pliocene to Recent and are primarily of Quaternary age (Juang 1993).

Early and late Miocene sedimentary rocks and Pleistocene volcanic rocks are exposed in the study area. The early Miocene rocks are the Wuchihshan Formation, the Mushan Formation and the Talio Formation. The late Miocene rocks are the Nanchung Formation and Kueichulin Formation. The Pleistocene rocks are the Kuanyinshan Formation, Linkou Formation and volcanic breccias. As given by Chang (1968), Chou (1962), Hsu (1967) and Hsu (1981), the surface geologic data in the study area are shown in Fig. 1.

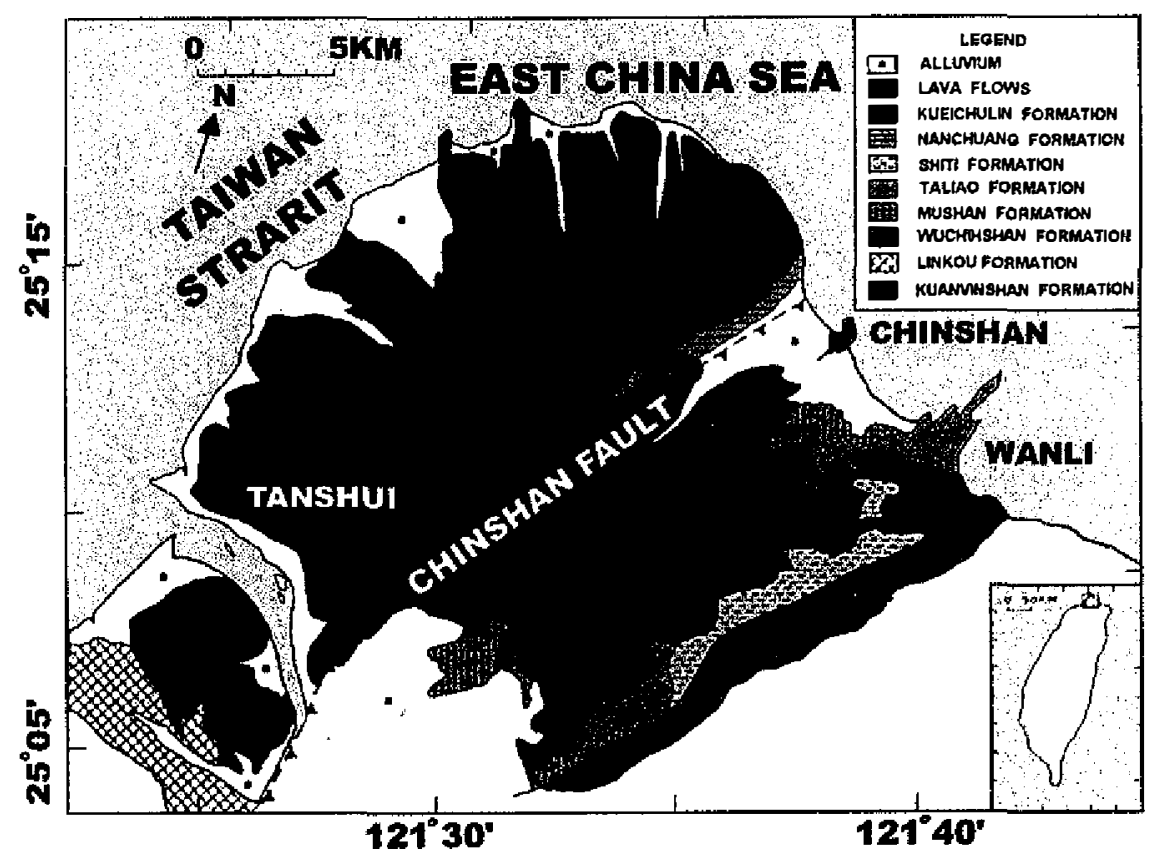

Fig. l. Simplified geologic structure map of the study area (after Chen et al. 1991). Early and late Miocene sedimentary rocks and Pleistocene volcanic rocks are exposed in the study area. The early Miocene rocks are the Wuchihshan Formation, the Mushan Formation and the Talio Formation. The late Miocene rocks are the Nanchung Formation and Kueichulin Formation. The Pleistocene rocks are the Kuanyinshan Formation, Linkou Formation and volcanic breccias. Two faults involved in the region are: the Chinshan and Kanchiao faults. 
The Tatun volcano group is one of the large volcano groups in Taiwan. It is situated at the northern corner of Taiwan island and represents a large-scale Quaternry volcanic intrusion. This group has its peak at Tatunshan, $1081 \mathrm{~m}$ in elevation, and is surrounded by Tsaikungkenshan $(832 \mathrm{~m})$ to the north, Shaukuanyinshan $(1063 \mathrm{~m})$ to the northeast, Mientienshan $(977 \mathrm{~m})$ to the west, Tatunnanshan $(980 \mathrm{~m})$ to the south, and Chihsingshan $(1120 \mathrm{~m})$ to the east. Chutzushan $(1103 \mathrm{~m})$ is located in the north of Chihsingshan. The andesitic lavas and pyroclastics are underlain by the Mio-Pliocene strata, which constitute the basement of the volcanic region. The volcano group comprises about 20 volcanoes and volcanic domes covering an area of approximately $350 \mathrm{~km}^{2}$. More than 15 lava flows and extensive pyroclastic accumulations are distributed in the central part of this volcano group that can be divided into subgroups named Tatunshan, Chutzushan, Chihsingshan, Shaokengliao, Neiliaoshan, Huangtsuishan, Nanshihshan, and Tinghuohsiushan. The three tuff-breccia formations are called the lower tuff-breccia, the Tatunshan tuff-breccia, and the upper tuff-breccia. The lavas are composed of various types of andesites, such as hornblende, pyroxene-hornblende, and hornblende-pyroxene andesites (Yen and Chen 1953).

\section{FIELD OBSERVATION AND DATA REDUCTION}

The magnetic survey was carried out using two portable magnetometers (Scintrex, ENVI Geophysical System) to measure the geomagnetic total intensity. One magnetometer was kept at the base station, reading at every ten minutes, to monitor the diurnal variation. The other magnetometer was carried by an observer to measure the total intensity at each station. 269 stations were set up in total. These magnetic stations were spaced about 1.5 to $2 \mathrm{~km}$ apart (Fig. 2). They were located absolutely far away from all visible or near-surface iron objects or power lines which may disturb the magnetic field. The locations and elevations of each station were determined with a GPS and on 1:5000 scale photographic contour maps. The data were accurate enough for present purpose so no level and plane table surveys were needed.

Accurate determination of magnetic anomaly is important because the data are to be investigated in terms of geologic structures. The main geomagnetic field due to the Earth's core and some part of the induced field must be removed completely from the survey data, especially for small-scale surveys. These components of observed field are termed the regional field. The IGRF 1995 for the field of internal and its secular variation was used in reducing survey data. Elevation corrections were made according to the expression for the vertical gradient $-0.0047 \mathrm{Ho}$ gamma/m, where Ho is the local value of the geomagnetic field intensity in Oersteds (Grant and West 1965). In this study area, Ho is 0.45100 Oersteds.

After the IGRF, diurnal variation, and elevation correction, the residual magnetic map was prepared at 100 gamma contour intervals, as shown in Fig. 3. Many small magnetic anomalies with an extent of only a few kilometers was scattered over the whole study area. Hsieh (1990) suggested that these negative anomalies might be caused by low-susceptibly material or by the hydrothermalism of the volcano activity. Some magnetic positive anomalies, distributed near Tanshui, Kuanyinshan and Samaoshan, were supposed to be caused by the dike (Hsieh 1990). Besides these small-scale anomalies, some large-scale anomalies of low ampli- 


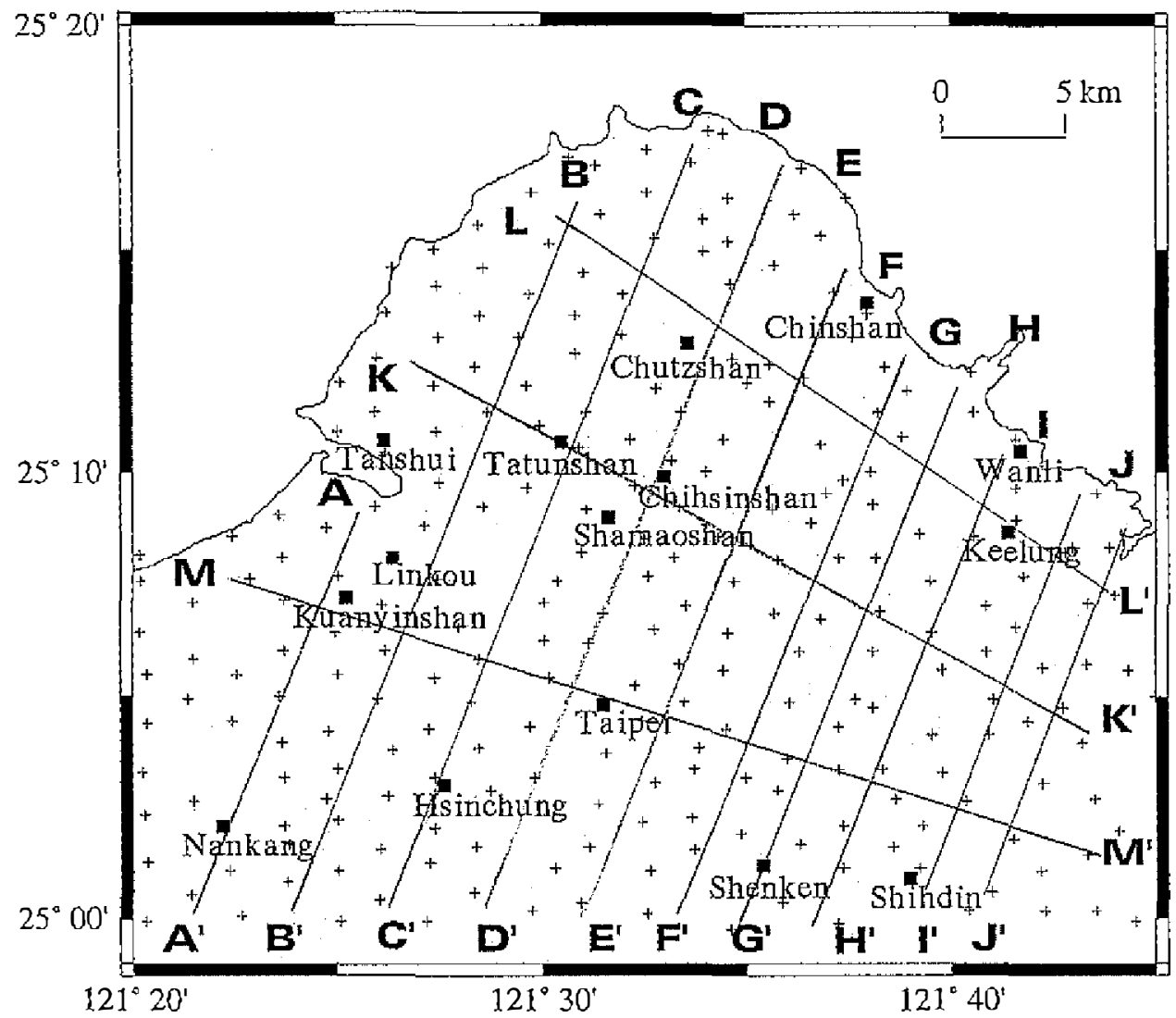

Fig. 2. Distribution of the magnetic stations (denoted by + ). Some location names referred in the text are also given. 13 lines (denoted by AA' BB' ... MM') show the location of magnetic profiles to be modeled for their magnetic basement depth.

tude are prominent features. The central part of the study area has negative anomalies with amplitude of 100 200 gammas, while both the eastern and southern parts have positive anomalies of 200 600 gammas. They are supposed to be caused by the deep-seated basement rocks.

\section{MODELING OF THE GEOMAGNETIC BASEMENT}

In order to infer the relief of magnetic basement, high frequency of magnetic anomalies must be removed. We use a simple first order filter to smooth the residual magnetic data. Figure 4 shows the smoothed geomagnetic anomaly with the input data shown in Fig. 3. Compare Fig. 4 to Fig. 3, we can find that the small-scale negative anomalies scattering from Chutzushan, Chihsingshan, Tatunshan, Keelung, and Wanli were removed. The contours pattern becomes gentler. The anomalies ranges decreased from 1300 gammas (in Fig. 3) to 850 gammas (in Fig. 4). Viewing the whole map, we can find that there exists a large-scale promi- 


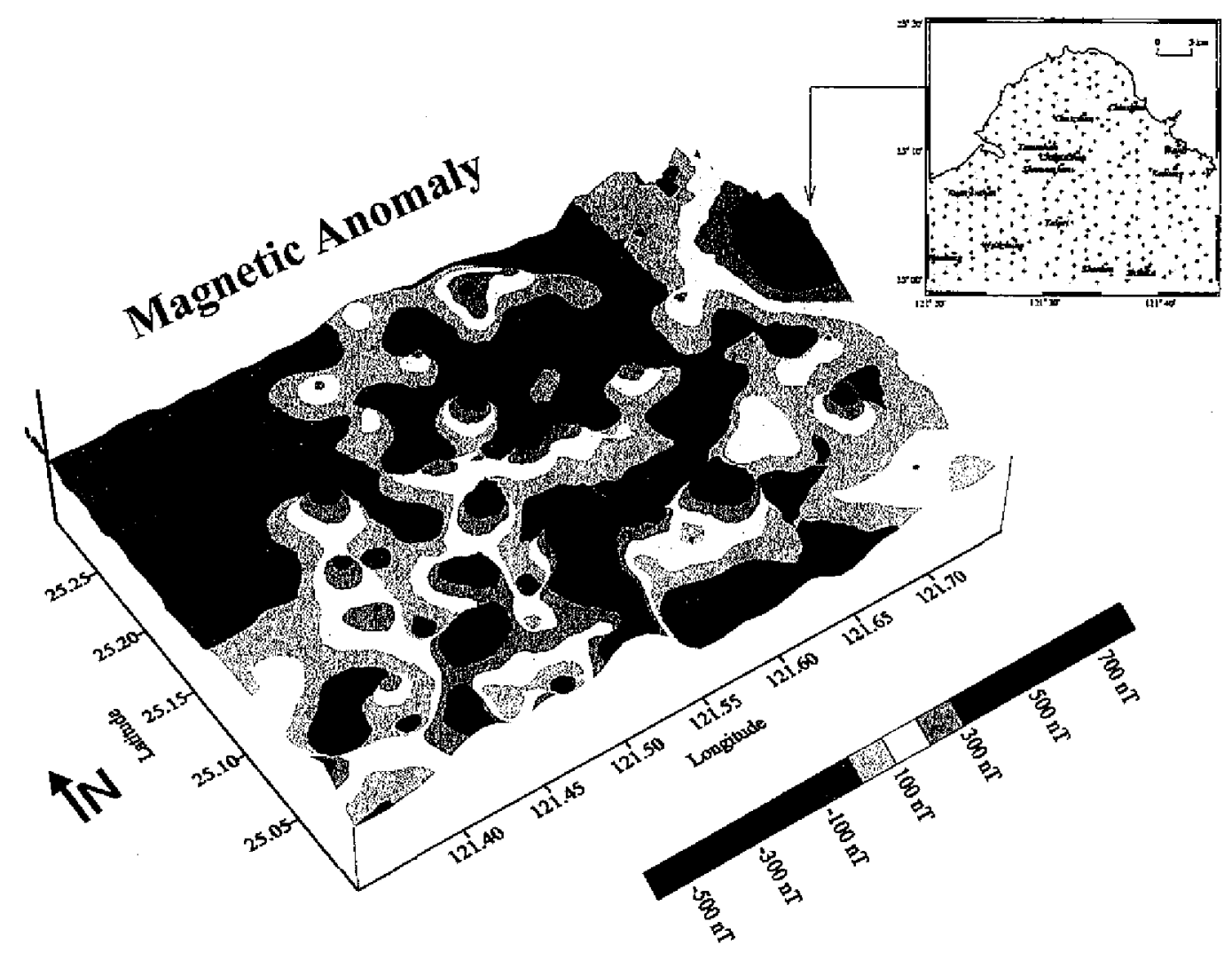

Fig. 3. Residual magnetic map after the IGRF, diurnal variation, and elevation correction, with 100 gamma of contour interval. Many small magnetic anomalies with an extent of only a few kilometers scatter over the whole study area. The central part of the study area has negative anomalies with amplitude of 100 200 gammas, while both the eastern and southern parts have positive anomalies of 200 600 gammas.

nent magnetic positive area, extending from Hsinchuang, Taipei basin to Shenkeng. The range of this positive anomaly is 200 to 400 gammas. An almost equivalent negative anomaly ranging from -299 to -350 gammas was located in the northeastern of this positive anomaly. These two anomalies were composed of a magnetic dipole with a trend in northeast direction. This dipole was also be evidenced in the study of Chang and $\mathrm{Hu}$ (1981).

Forward modeling is an "art" of estimating the geometry of the source of the distribution of magnetization within the source by trial-and-error modeling. Many different forward modeling algorithms are available with which to calculate the precise field of a hypothetic source. The result is compared with the observed data, and the model is adjusted in order to improve the fit for a subsequent comparison. The decision on how to adjust the model at each iteration in the trial-and error approach is subjective and can be time-consuming. Consequently, various workers have written algorithms to perform the forward-modeling iteration by computer. 


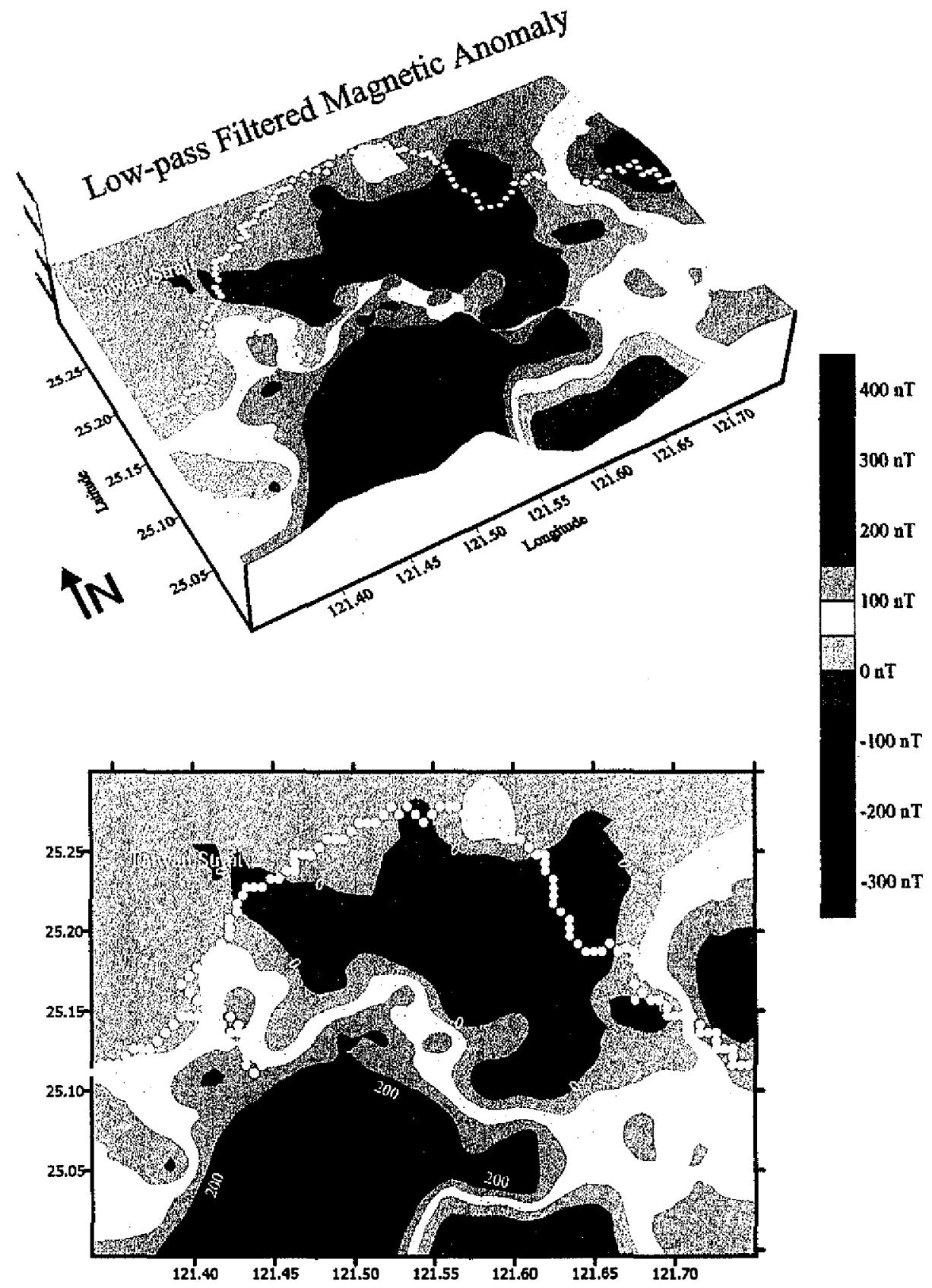

Fig. 4. Smoothed magnetic anomalies by applying a low-pass filter to the magnetic anomaly shown in Fig. 3. Comparing to Fig. 3, the contours pattem becomes gentler and the small-scale negative anomalies scattering from Chutzushan, Chihsingshan, Tatunshan, Keelung, and Wanli were removed. 
The theoretical profile is calculated from the initial model, "goodness of fit" is determined between the observed and the calculated profiles, one or more body parameters are adjusted so that the fit can be improved, and the field is then recalculated.

In this study, we used the algorithms derived by Hsu et al. (1996) to do the profile (2-D) and surface (3-D) forward modeling. The profile modeling was described above. The surface modeling work includes dividing the source region into a number of small elements (or cells), calculating its theoretical magnetic anomaly above these elements. In the first stage, the observed surface residual magnetic data was profiled to infer its geometry of the depth to sedimentary basin or magnetic basement. All of the results of profiles (as shown in Appendix) were compiled to obtain surface basement depth relief data. Figure 5 shows the magnetic basement relief. In order to confirm and verify the "truth" or "fit", we used the result of the basement depth data as the model to calculate its theoretical magnetic anomaly.

The depth to the top of the source is a useful tool for finding depths of sedimentary basins, and sometimes for locating major structures in basement rocks. Calculation of depth to source or depth to bottom of source can be made from the shape of anomalies, or the shape of the power spectrum computed from magnetic data. In this study, we utilized the enhanced analytic signal technique derived by Hsu et al. (1996) to do the forward modeling. In order to model the depth to basement, ten profiles roughly trending in northwestern-southwestern and three profiles trending in northwestern-southeastern were selected (Fig. 2). The observed magnetic data along the profile were obtained by projection from the surface magnetic residual data (shown in Fig. 4). The program for profile forward modeling provided by Hsu was used for the theoretical calculation. 45000 gammas, $-2.5^{\circ}(\mathrm{NW})$ and $35^{\circ}$ were assumed as the average total intensity, magnetic declination and magnetic inclination, respectively, to perform the calculation. The observed and calculated magnetic values were matched as closely as possible by trial and error. If the difference between calculated and observed values is greater than 20 gamma, the model will be modified, until all of their differences are smaller than 20 gammas. The optimum results of the depth to the magnetic basement beneath the thirteen profiles are shown in Appendix. In general, the calculated and the observed magnetic anomalies fit well. Some misfits may be caused by the interpolations of 2-D contours into a 1-D profile. The inferred ID profile depth models were compiled to obtain the 2-D surface depth models. Figure 5 shows the result of the 2-D relief of depth to magnetic basement. It indicates that the surface of the basement dips gently from north to south, ranging from $2.6 \mathrm{~km}$ to $6.0 \mathrm{~km}$. There are two domeshaped basement highs underneath Tatun volcano and Kuanyinshan volcano, respectively. The summit of the basement is located in the northeast of Chihshishan. It is supposed that the initial eruption point of Chihshinshan is under this area. The feature of basement under the Tatun volcano shows a similar pattern to the topography of the distribution of the Tatun volcano group. Around the Tanshui and Bali area, the depths of basement range from 3 to $4 \mathrm{~km}$, that is consistent with the suggestion of Chai and Pan (1975). Bosum et al. (1971) inferred that the depths of basement under the Kuanyinshan Shelf, offshore northern Taiwan, ranging from 3 to $7 \mathrm{~km}$, are consistent with our results. The continuation in the sea-land boundary in the northwest of Taiwan is pretty good. In the northeast, the depths of basement range within $4 \sim 5$ $\mathrm{km}$ with a trend dipping to southwest. It is consistent with the topography of the sea bottom in the northeast of Taiwan. Under most of the Taipei basin area, the depths vary everywhere, 

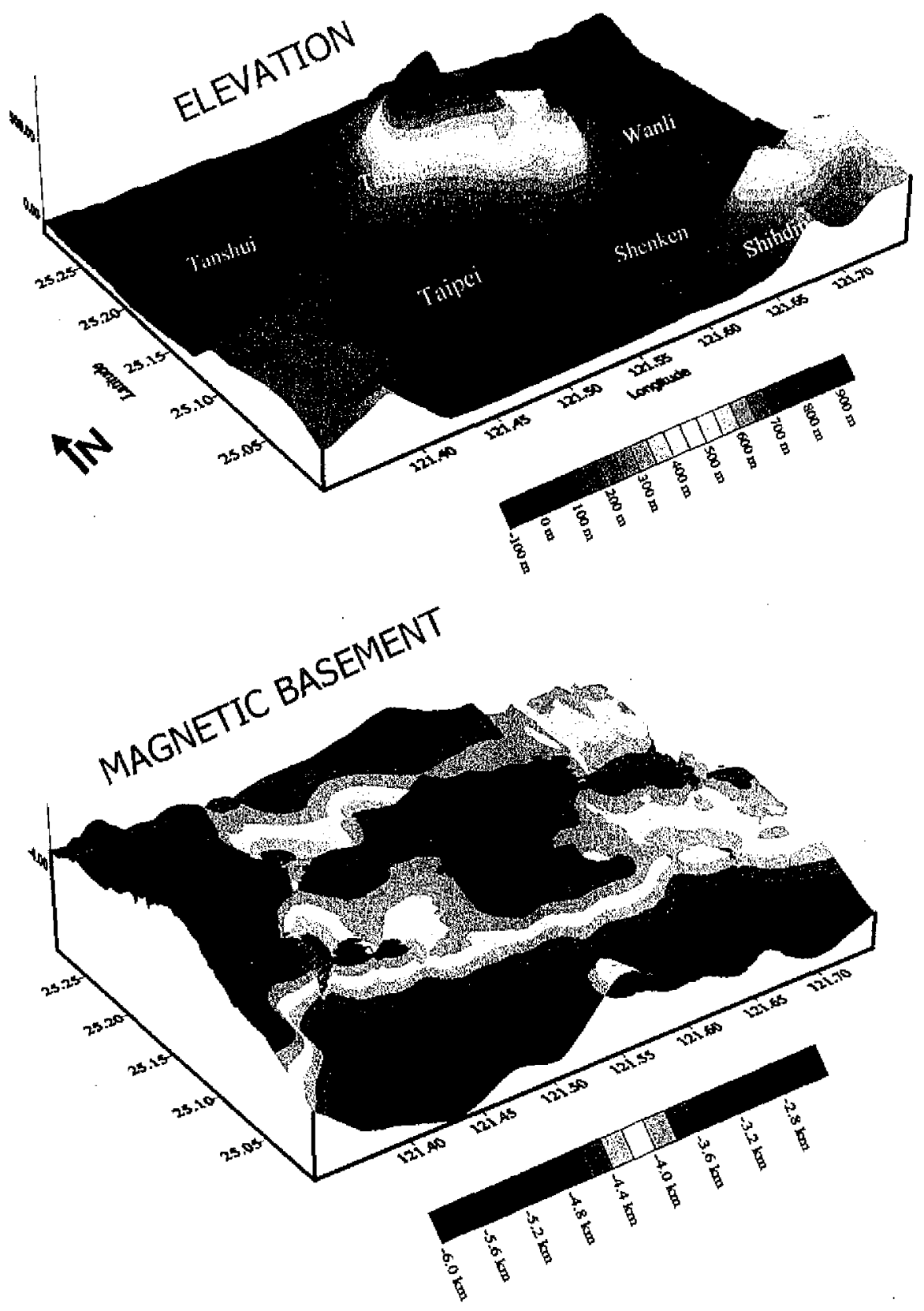

Fig. 5. Magnetic basement relief compiled from the 13 profiles. The elevation map is shown in top. The surface of the basement dips gently from north to south, ranging from $2.6 \mathrm{~km}$ to $6.0 \mathrm{~km}$. There are two dome-shaped basement high underneath Tatun volcano and Kuanyinshan volcano, respectively. The summit of the basement is located in the northeast of Chihshishan. 
with an average of 4 to $5.5 \mathrm{~km}$. That the thickness of the Miocene layer in north of Taiwan is about $3 \mathrm{~km}$ as suggested by Chou (1976), seems to be reasonable.

In order to have an advanced understanding of the relationship between geologic activity and topography, we compiled the depths contour of magnetic basement with elevation relief data (shown in Fig. 5). We found that these two kinds of data matched well in most of the study area. The basement high always shows relative high elevation while basement low relates to a low elevation. In general, the outline of the distribution of volcanoes, surveyed by surface geology, in the study area relate well to distinct magnetic basement highs. A converse appears in the south of the study area where a basement low relates to elevation high. This can be understood by considering that the mountainous area is rifted by compression force owing to plate tectonics.

In order to estimate the goodness of the modeling fit, we calculate the theoretical magnetic anomaly by taking the result of the basement as the model. The whole area was blocked

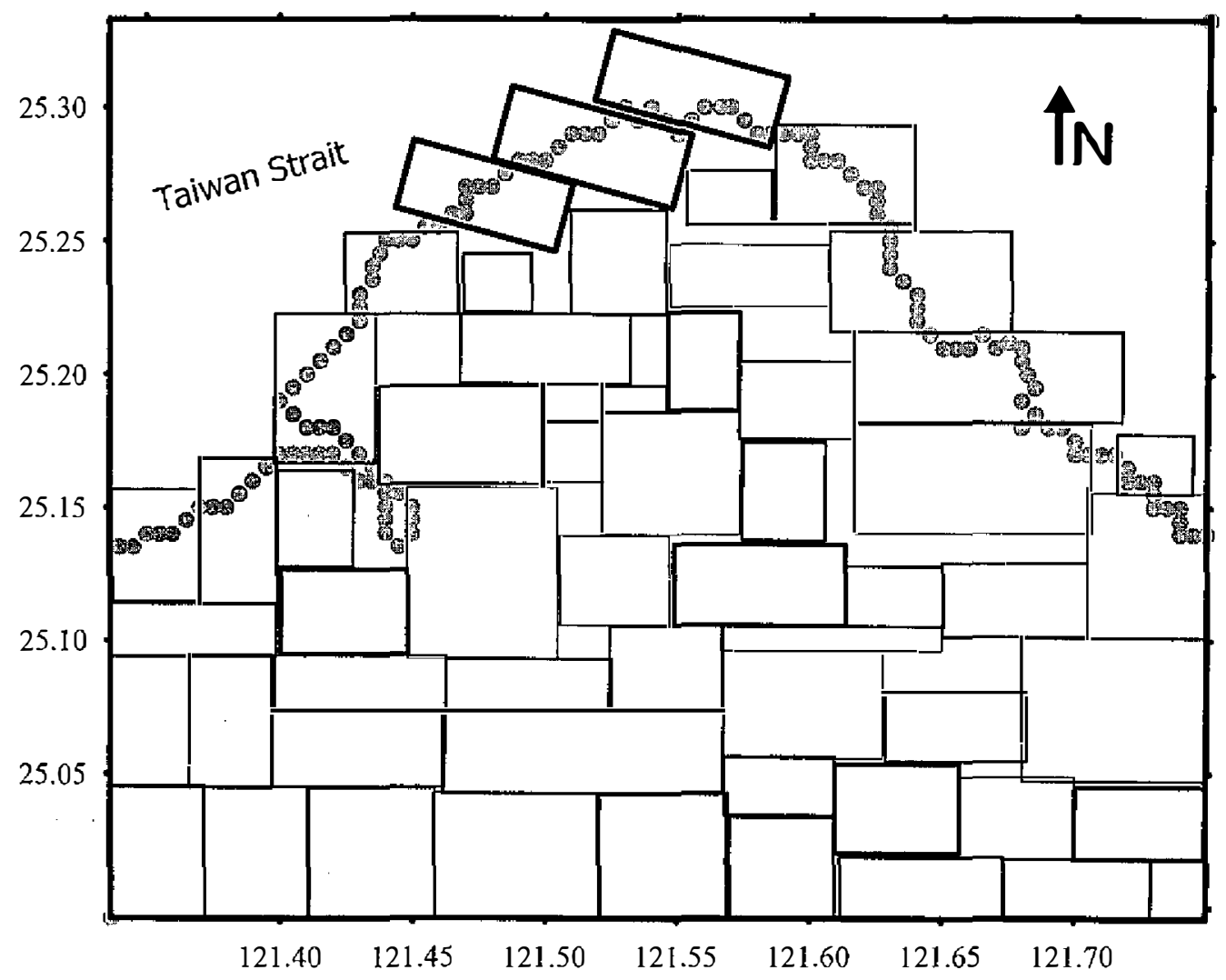

Fig. 6. Boundaries of the elements (top face of each prism). Contours of the magnetic basement relief in each element were averaged. The value will be taken as the mean of the prism and the corresponding magnetic anomaly above these prisms will be calculated. 


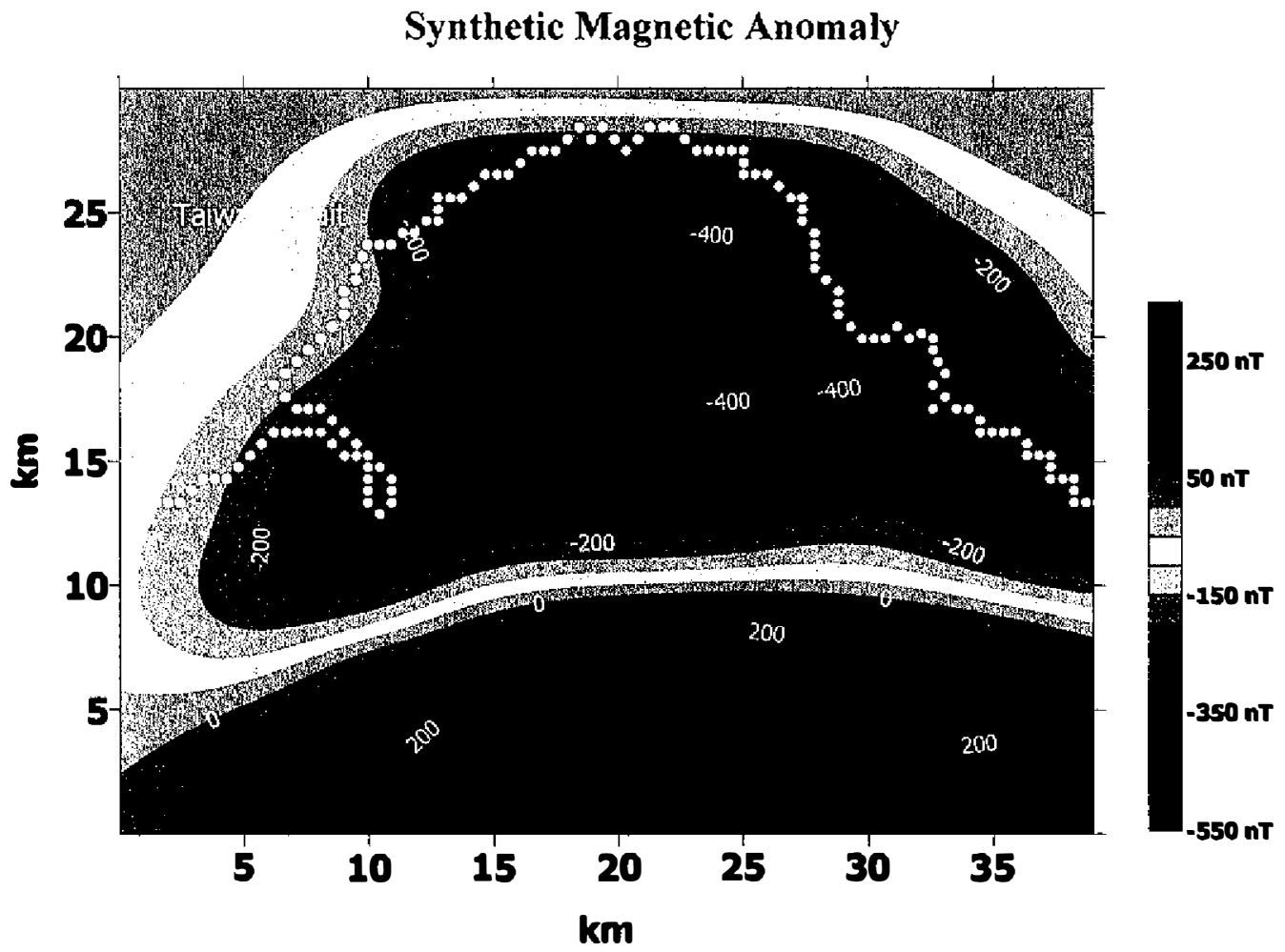

Fig. 7. Theoretical magnetic anomalies calculated from the element model shown in Fig. 6.

into 50 elements. The average depth within each element was calculated and taken as the representative value for that element. 50 depth data within this area were used as the 2-D model to calculate its corresponding magnetic anomaly. Figure 6 shows the boundaries of each block. The theoretic magnetic values derived by this model are shown in Fig. 7. Comparing Fig. 6 with Fig. 4, we can find that they are quite similar to each other.

\section{CONCLUSIONS}

A detailed magnetic survey has been conducted in the northern area of Taiwan to infer the magnetic basement. The residual anomalies map was obtained after the appropriate corrections. The interface between magnetic basement and the sedimentary rocks was modeled with the residual anomaly data. The results in this study can be summarized as follows:

(1) The distribution pattem of residual anomaly shows some specific characterizations that are considered to be produced by the magnetic basement. The residual anomaly high is located in the southwestern part of the survey area, including most of the Taipei basin, Hsinchuang, and Kuanginshan. There are two distinct anomaly lows. One is located under Tatun and Chihsingshan volcanoes and the other distributing under Shenkeng and Shiding area. 
(2) The depths of the magnetic basement range from 2.6 to $6 \mathrm{~km}$. The relative high is located under the Tatun volcano group, near Chishinshan. It is suggested that the eruption of Chishinshan initiated from the hump of the basement to the south and southwest direction.

(3) The other basement high located in the west of Tatunshan surrounding Tanshui and Linkou area. The depths range within 3 to $4 \mathrm{~km}$. The feature of this basement high is supposed to be dominated by the eruption of Kuanyinshan. The third basement high near the northeastern area under Wanli, Keelung area has a depth range of $4 \sim 5 \mathrm{~km}$.

(4) The good correlation between the terrain elevation and the relief of magnetic basement can be found under the Tatun volcano group area. This indicates that the terrain relief of the Tatun volcano group is relative to the activity of volcanoes.

(5) The depths of basement under the mountainous area, in the southeast and southwest of the survey area, show relatively low compared to the central part. This is consistent with the other studies. The thick sedimentary rocks under this area are founded by the tectonics after the basement formed.

Acknowledgements The authors thank many useful suggestions from Prof. W. S. Chen and Dr. C. H. Lin to improve the manuscript. We also would like to express our thanks to two anonymous reviewers for their useful comments. This work was supported by the National Sciences Council, ROC under the Grants NSC 87-2119-M-003-001.

\section{REFERENCES}

Bosum, W., G. D. Burton, S. H. Hsieh, E. G. Kind, A. Schreiber, and C. H. Tang, 1971: Aeromagnetic survey of offshore Taiwan. CCOP Technical. Bull., ECAFE 3,1-34.

Chai, H. S., and Y. S. Pan, 1975: The magnetic model study of the northwest offshore of Taiwan. Petro. Geol. Taiwan, 12, 131-140.

Chang, Stanley, S. L., 1968: Regional stratigraphic study of the Lower Miocene Formations in northern Taiwan. Petrol. Geol. Taiwan, 6, 47-70.

Chang, Stanley S. L., and C. C. Hu, 1981: Gravity and magnetic anomalies of Taiwan and their tectonic implication. Mem. Geol. Soc. China, 4, 121-142.

Chen, C. H., and Y. J. Wu, 1971: Volcanic geology of the Tatun geothermal area, northern Taiwan. Proc. Geol. Soc. China, 14, 5-20.

Chen, C. S., and C. H. Hsieh, 1994: Electrical strata of Taipei basin. Central Geol. Surv. Special pub., 8, 299-317.

Chen, K. J., 1998: S-wave attenuation structure in the Taiwan area and its correlation to seismicity. TAO, 9, 97-118.

Chen, K. J., and Y. H. Yeh, 1991: Gravity and microearthquake studies in the Chinshan Tanshui area, northern Taiwan. TAO, 2, 35-50.

Chen, K. J., Y. H. Yeh, H. Y. Yen, and C. H. Lin, 1995: Seismologic studies in the Chinshan fault area. J. Geol. Soc. China, 38, 335-353.

Chou, J. T., 1962: Stratigraphic and sedimentary study of the Mushan Formation in northern Taiwan. Petol. Taiwan, Mr. King's Jubilee, Volume (1), 87-119. 
Chou, J. T., 1976: Sedimentology and paleogeography of the Miocene clastic sequence in northern Taiwan, with emphasis on its sandstones. Petrol. Geol. Taiwan, 13, 83-118.

Grant, F. S., and G. F. West, 1965: Interpretation theory in applied Geophysics. McGraw-Hill Book Co., 583p.

Hsieh, C. H., S. H. Hsieh, and C. W. Huang, 1994: A field survey of the Taipei basin by the shallow seismics and well loggings. Central Geol. Surv. Special pub. 8, 52-55.

Hsieh, T. C., 1990: Subsurface geologic and geophysical studies in the Tatun volcanic area. Nat'l Central Univ. Master Thesis.

Hsu, M. Y., 1967: Geology of the coal field between Chinshan and Shihmen, Taiwan. Bull. Geol. Surv. Taiwan, 19, 15-26 (Chinese), 9-14 (English).

Hsu, S. K., J. C. Sibuet, and C. T. Shyu, 1996: High-resolution detection of geologic boundaries from potential-field anomalies: An enhanced analytic signal technique. Geophysics, 61, 373-386.

Hsu, T. L., 1981: Geological map of Taiwan, Linkou sheet, Sanchih sheet, and Taipei sheet, Geol. Surv. R.O.C.

Juang, W. S., 1993: Diversity and origin of Quaternary basaltic magma series in northern Taiwan. Bull. National Museum Sci., 4, 125-166.

Lee, C. T., and Y. Wang, 1987: Paleo stress change due to the Pliocene-Quaternary arccontinent collision. Mem. Geol. Soc. China, 9, 63-86.

Lee, J. F., C. H. Lin, D. C. Lai, T. W. Su, Z. L. Chiu, and C. J. Zeng, 1999: The formation of Taipei basin. Central Geol. Surv. Special pub.,11, 207-226.

Suppe, J., 1981: Mechanics of mountain building and metamorhism in Taiwan. Mem. Geol. Soc. China, 4, 67-89.

Suppe, J., 1984: Kinematics of arc-continent collision, flipping of subduction, and back-arc spreading near Taiwan. Mem. Geal. Soc. China, 6, 21-34.

Tsai, Y. B., 1978: Plate subduction and the plio-pleistocene orogeny in Taiwan. Petrol. Geol. Taiwan, 15, 1-10.

Tsai, Y. B., T. L. Teng, J. M. Chiu, and H. L. Liu, 1977: Tectonic implications of the seismicity in the Taiwan region. Mem. Geol. Soc. China, 2, 13-42.

Tsai, Y. B., Z. S. Liaw, T. Q. Lee, M. T. Lin, and Z.H Teh, 1981: Seismological evidence of an active plate boundary in the Taiwan area. Mem. Geol. Soc. China, 4, 143-154.

Tzou, Y. H., and G. K. Yu, 1987: Subsurface structure of Tatun Volcano Group area inferred from the gravity data. Bull. Geophys., NCU, 27-28, 45-60.

Wang, C. Y., C. C. Sun, W. C. Shao, and Y. L. Tsai, 1994: Seismic strata in Kuantu-Lutzo area, Taipei basin. Central Geol. Surv. Special pub., 8, 361-386.

Wu, F. T., 1978: Recent tectonics of Taiwan. J. Phys. Earth, 26 (suppl.), 265-299.

Yang, C. H., T. C. Shei, and C. C. Lue, 1994: Gravity and magnetic studies in the Tatun Volcanic region. TAO, 5, 499-514.

Yen, T. P., and P. Y. Chen, 1953: Geologic map of Taiwan, nos. 5 and 9 (scale 1:50,000). Geol. Surv. Taiwan.

Yen, T. P., Y. H., Yzou, and W. H. Lin, 1984: Subsurface geology of the region of the Tatun Volcano Group. Petrol. Geol. Taiwan, 20, 143-154. 


\section{APPENDIX}

Results of inferred magnetic basement depth along the 13 profiles (AA' MM'). The calculated (dash line) and the observed anomaly (solid line) are also shown (top). The magnetic susceptibility $(\kappa)$ is dimensionless and always is shown in C.G.S. unit.

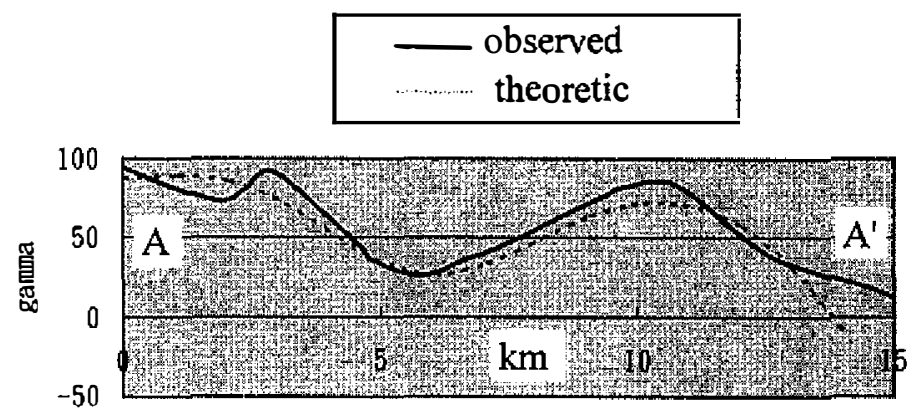

(a)
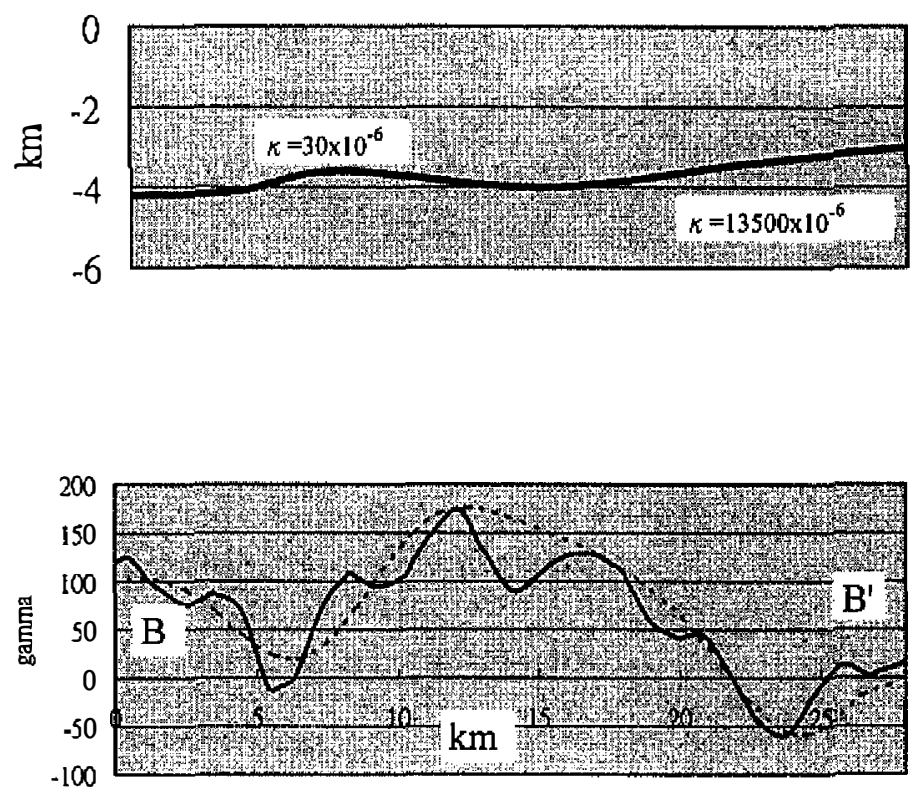

(b)

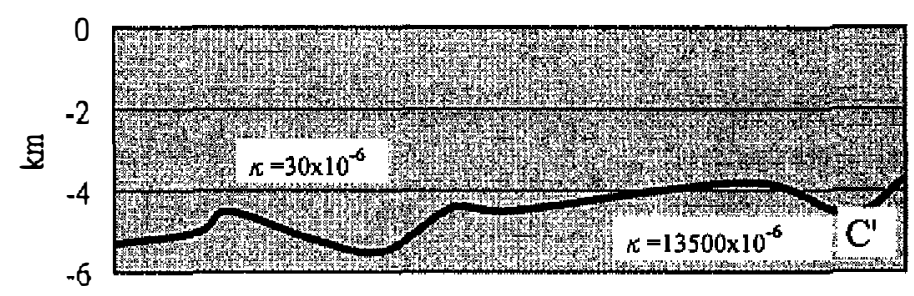




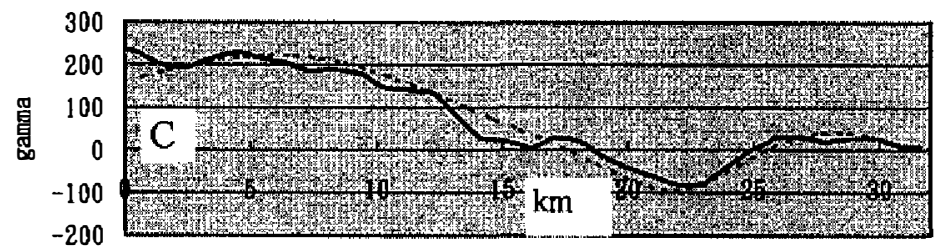

(c)
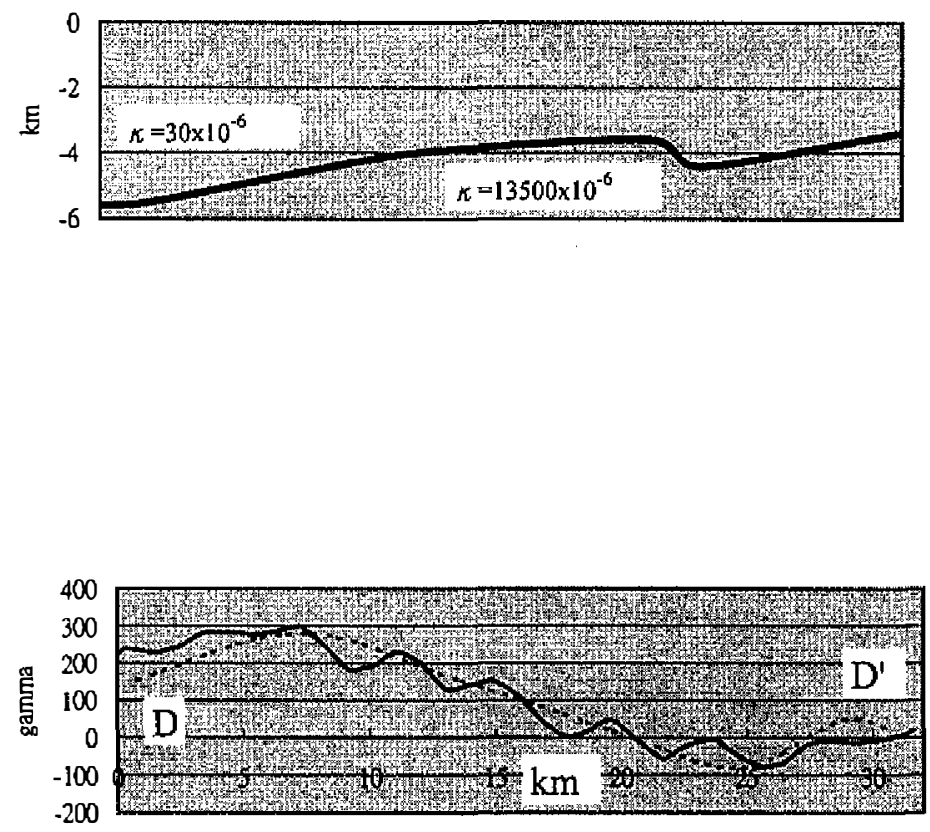

(d)

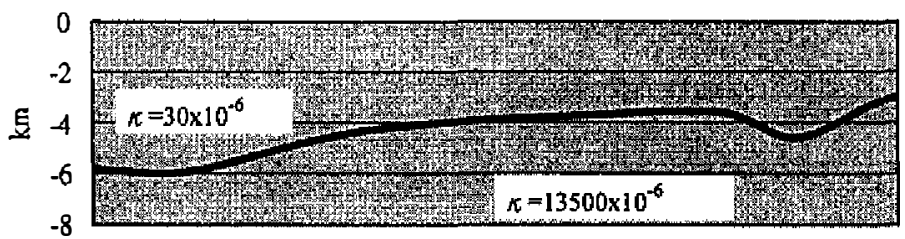




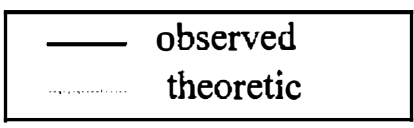

(e)
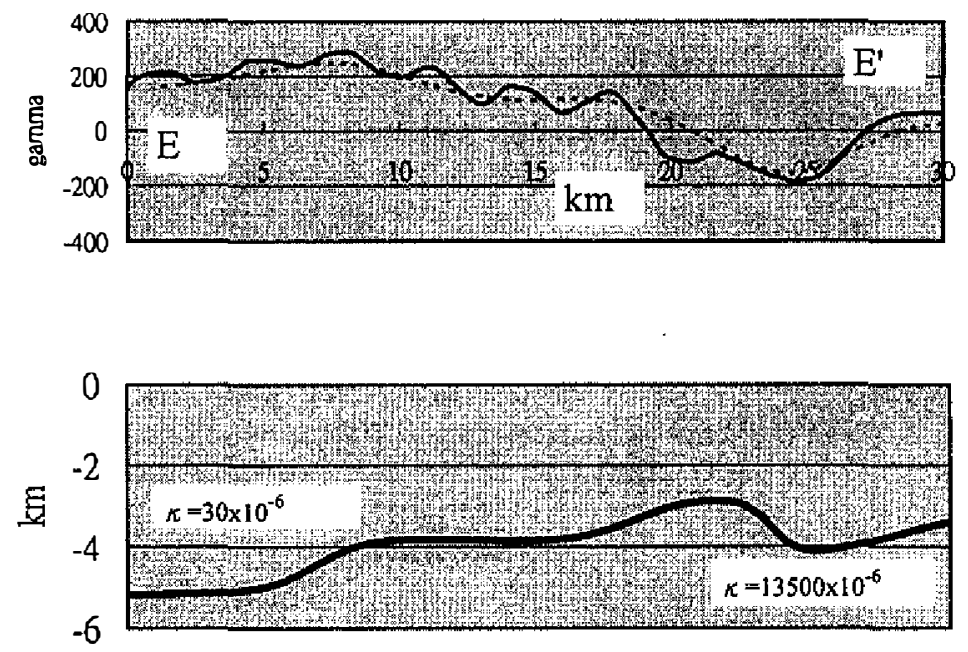

(f)
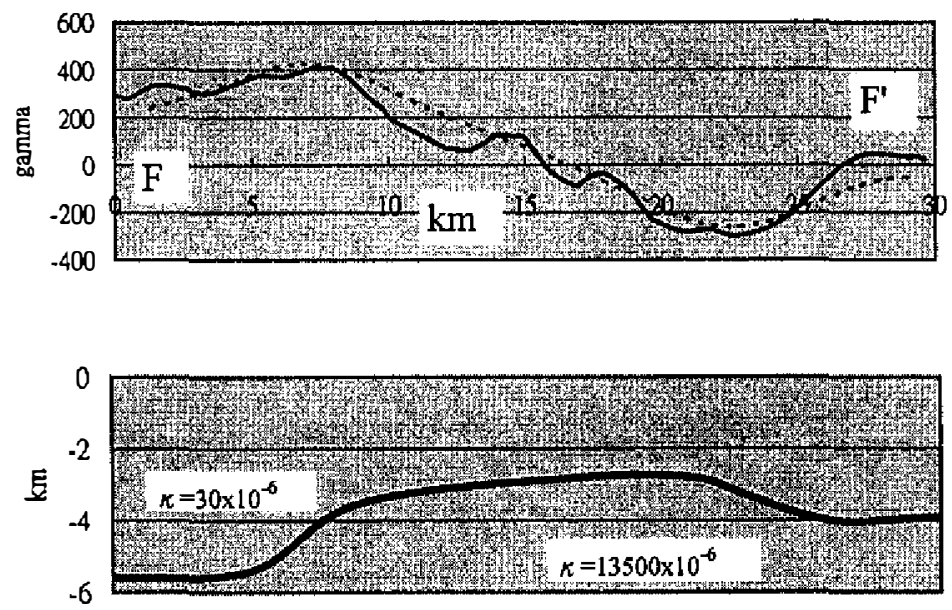

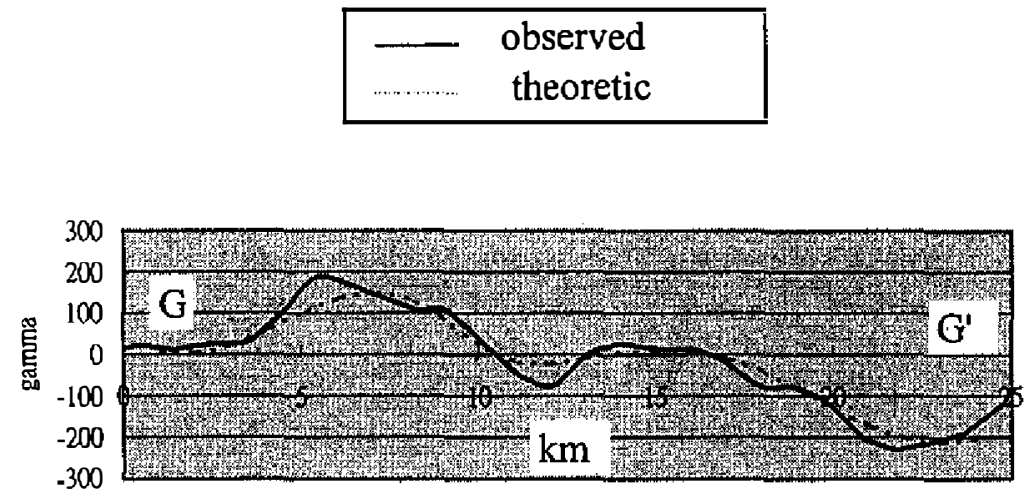

(g)

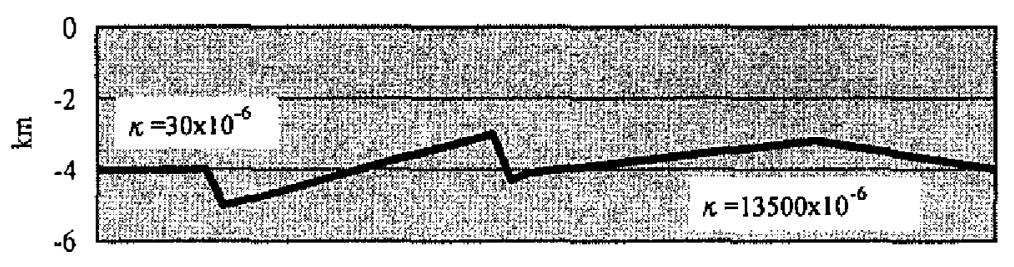

(h)
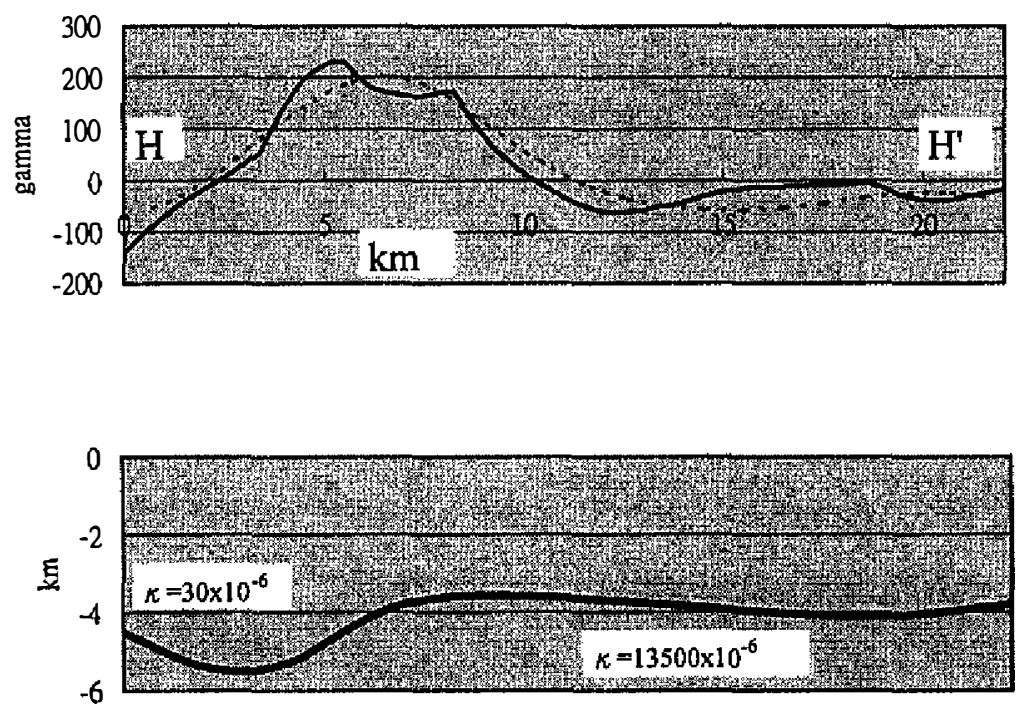

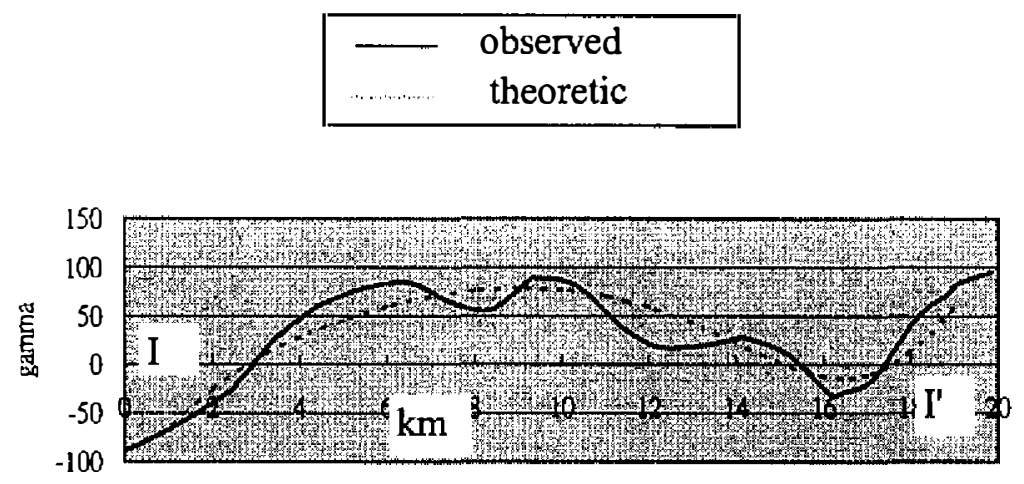

(i)
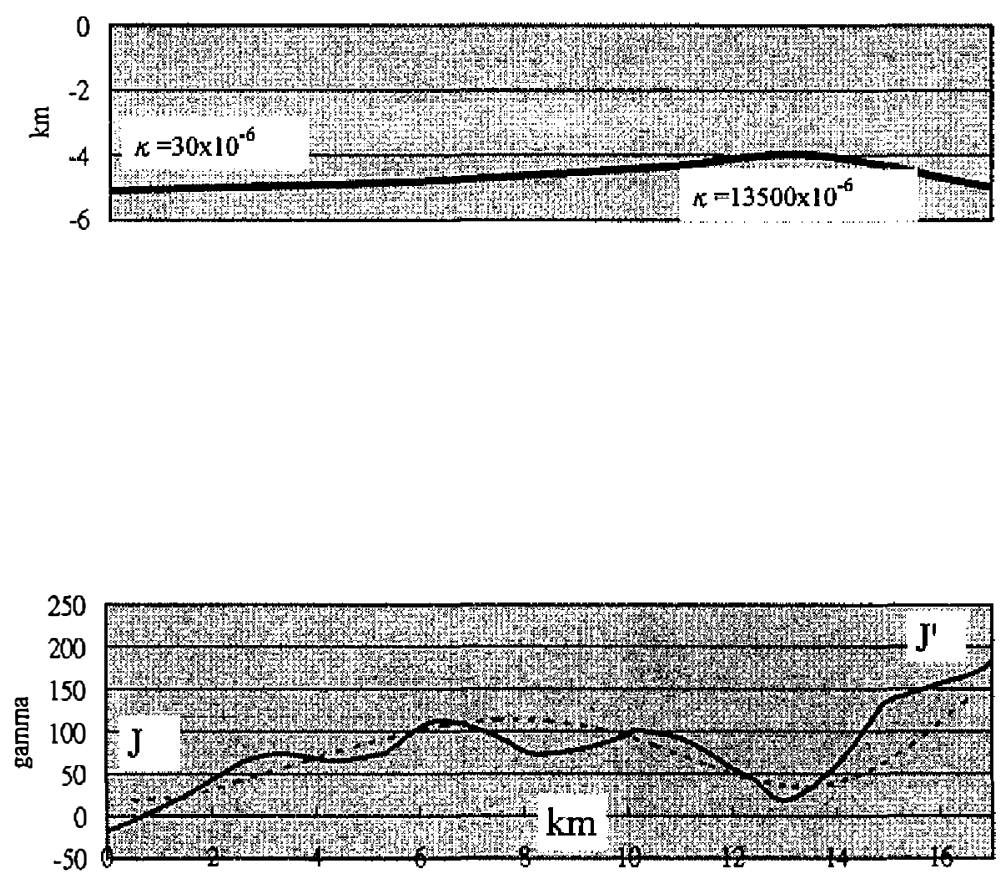

(j)

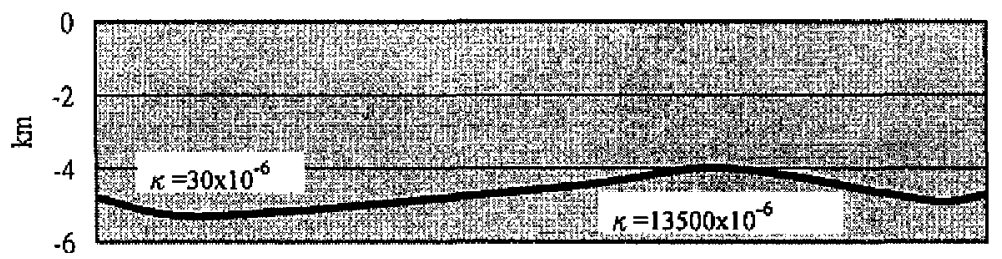



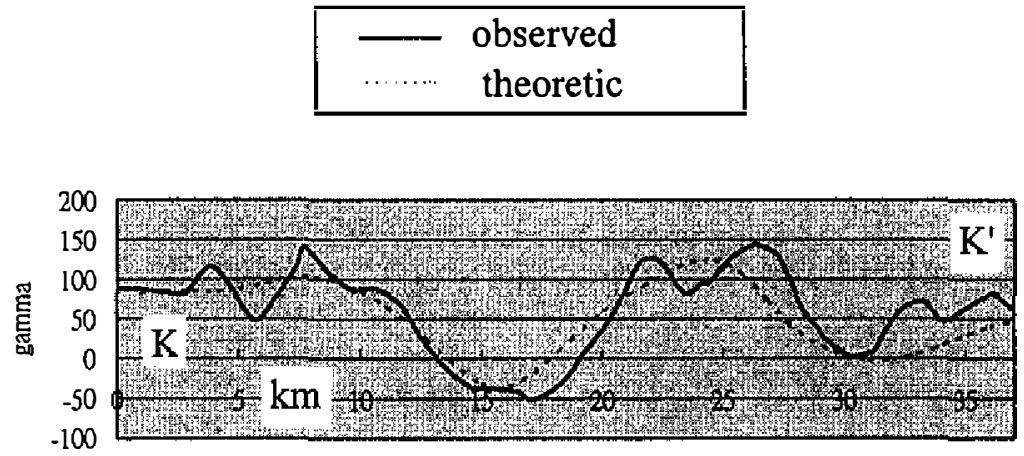

(k)
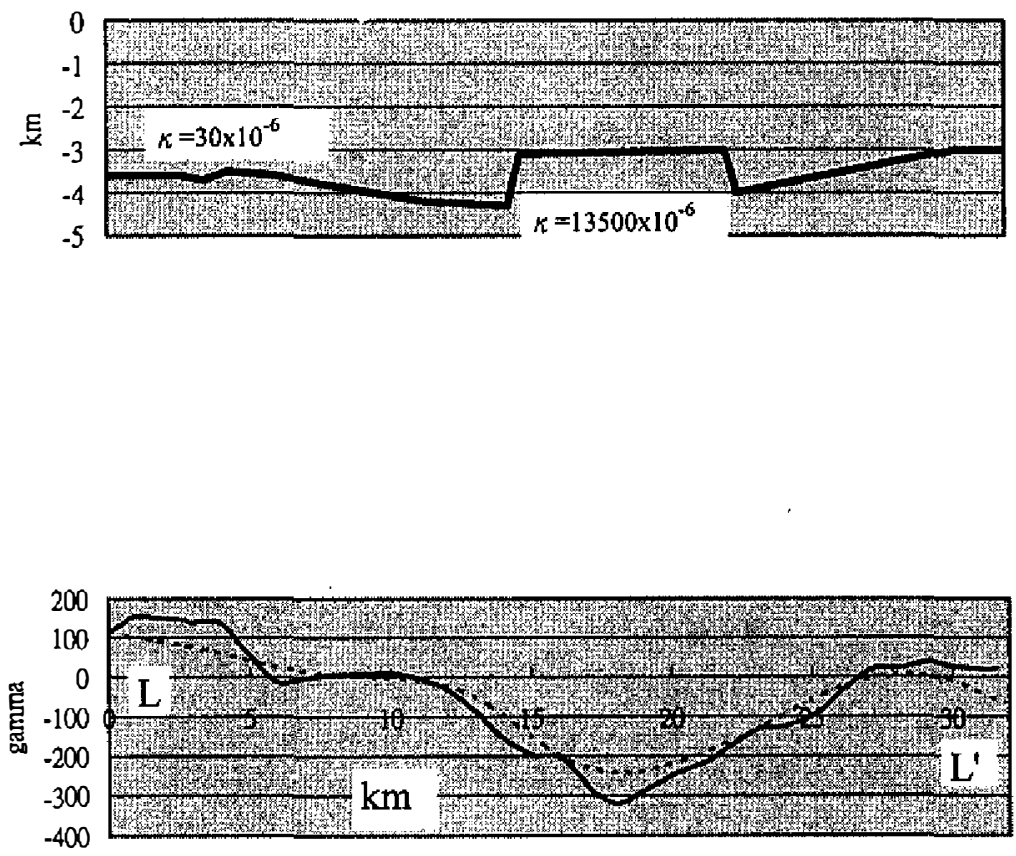

(l)

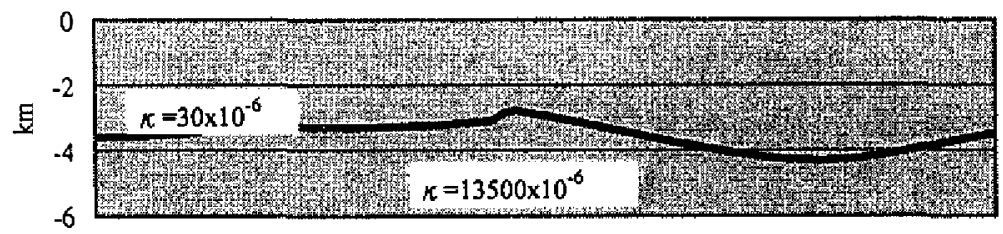




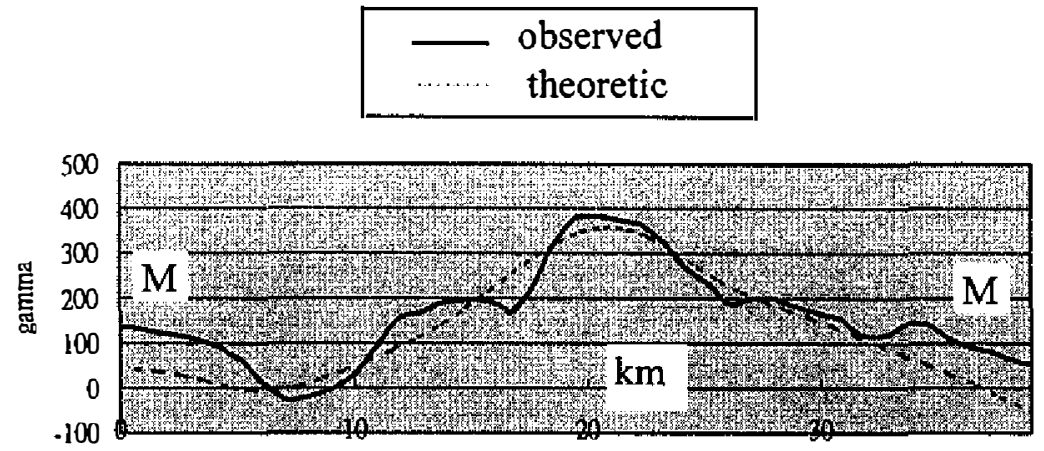

(m)

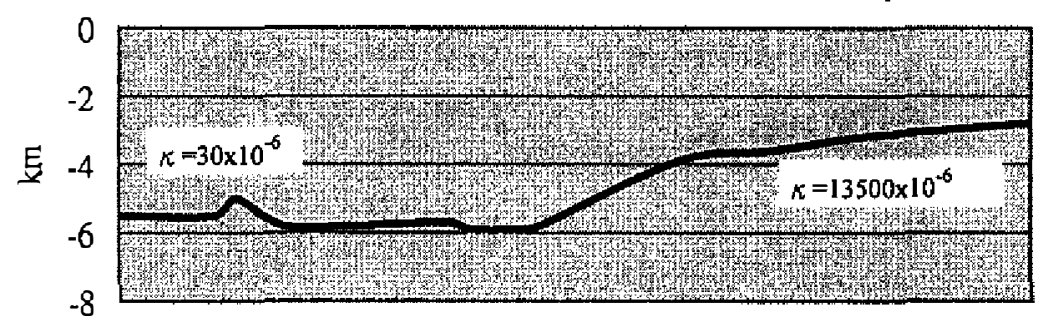

